\title{
A gestã̃o da qualidade em serviços de informação no Brasil: uma nova revisão de literatura, de 1997 a 2006
}

Doutora e Mestre em Ciências da Comunicaão pela Escola de Comunicaçãa e Artes da Universiddade de São Paulo - ECA/USP; Docente do curso de Pós-graduação da Pespspp (Fundação Escola de Sociologia e Políitica de São Paulo); Consultora em Gestão da Qualidade e do Conhecimento.

Professor Associado, Chefe do Departamento de biblioteconomia e Documentação da Escola de Comunicaçōes e Artes da Universiddade de São Paulo - CBD/ECA/USP.

Descreve a implantação da gestão da qualidade em serviços de informação no Brasil, por meio de revisão de literatura nacional, com o objetivo de complementar a revisão de literatura publicada em 1998 e apresentar um novo panorama, com trabalhos publicados e divulgados a partir de 1997 , objetivando contribuir para o avanço das discussões a respeito da aplicação da gestão da qualidade em serviços de informação no Brasil e adicionar um novo estudo teórico sobre o tema.

Palavras-chave: Gestão da qualidade; Serviços de informação 


\section{Introdução}

Na literatura nacional e internacional, os serviços de informação têm participado de iniciativas relacionadas à gestão da qualidade, principalmente pela influência das instituições mantenedoras que, ao se integrarem a programas de qualidade, envolvem diretamente esses serviços em seus conceitos e fundamentos ou através da iniciativa dos próprios profissionais de informação que vislumbram uma oportunidade para melhoria e avanço dos serviços prestados. Independente da razão que leva um serviço de informação a buscar, na gestão da qualidade, parâmetros para melhorar suas atividades e evoluir as práticas gerenciais implantadas, destaca-se a progressiva preocupação demonstrada em inúmeras pesquisas realizadas, nos relatos de experiência e nos estudos teóricos e acadêmicos que vêm sendo divulgados e que estão contribuindo diretamente para evidenciar que a gestão da qualidade já ocupa lugar de destaque na teoria de administração dos serviços de informação.

No Brasil, datam do início da década de 1990 os primeiros relatos sobre a aplicação da qualidade em serviços de informação que eram, basicamente, comunicações sobre a aplicação de fundamentos da qualidade nesses serviços. Alguns desses trabalhos são pioneiros, pois adaptaram aos serviços ferramentas até então utilizadas na indústria, com todas as dificuldades de adequação e até mesmo de entendimento. Dessa fase, destacam-se Areco (1992), Belluzzo e Macedo (1993), Pinto (1993), Rocha e Gomes (1993), Rocha Filho (1995), Silva et al( I 995), Vergueiro (1995) e Barbalho (I 995 e 1996). Essa primeira fase da literatura nacional, período compreendido entre o início da incidência do tema na literatura nacional especializada e o final de 1996, foi estudada por Valls e Vergueiro (1998), tendo sido então elaborado um panorama geral, visando a contribuir para a sistematização do tema no país e possibilitar, também, uma reflexão teórica, uma vez que os autores identificaram que a literatura publicada até então não apresentava uma base sólida, com o tema, de forma geral, sendo abordado isoladamente, sem uma sistematização mais aprofundada.

De 1997 até o presente ano, a evolução nas organizações foi acentuada, em razão das mudanças sociais e econômicas da última década e certamente a administração dos serviços de informação sofreu alterações em razão da necessidade de melhoria dos serviços prestados e da elevação dos níveis de qualidade oferecidos aos seus usuários. Nesse sentido, o objetivo do presente artigo é complementar a revisão de literatura publicada em 1998 e apresentar um novo panorama, com trabalhos publicados e divulgados a partir de 1997, objetivando contribuir para o avanço das discussões a respeito da aplicação da gestão da qualidade em serviços de informação no Brasil e adicionar um novo estudo teórico sobre o tema. 


\section{Aplicação dos conceitos de gestão da qualidade em serviços de informação no Brasil}

Na revisão divulgada em 1998, a partir da análise da literatura disponível, foram apresentadas algumas considerações:

- Forte tendência de aplicação isolada das metodologias de gestão da qualidade nos serviços de informação, sem uma relação direta com projetos de qualidade total nas organizações;

- $\quad$ conceito de qualidade geralmente vinha sendo apresentado de forma pontual, relacionando-se muito mais com fazer bem feito do que com o conceito proposto pela gestão da qualidade total;

- A pouca literatura disponível estava mais centrada em relatos de experiências, muitas vezes sem suporte teórico.

Podemos concluir que as tendências identificadas são resultantes do próprio estágio em que o tema estava sendo estudado no país, de maneira exploratória e pioneira, e que, a partir desses trabalhos e de suas recomendações, muitos outros pesquisadores e dirigentes de serviços de informação passaram a estudar o tema, ampliando sua base teórica e, principalmente, analisando e criticando sua aplicabilidade à prestação de serviços de informação. Além disso, é possível evidenciar estudos acadêmicos sendo publicados, indicando que a questão da qualidade, até então abordada de maneira pragmática, ganhava aos poucos espaço nas escolas e faculdades de biblioteconomia e ciência da informação, como tema de estudos e análises teóricas mais aprofundadas. Observa-se, também, as escolas de engenharia de produção abordando a prestação de serviços de informação e validando suas pesquisas em bibliotecas, principalmente ligadas a universidades. Destacam-se, neste contexto, os estudos acadêmicos de Barbalho (1995), Ferreira (1997), Valls (1998), Santos (2000), Vergueiro (2000), Xavier (200 I), Amboni (2002), Andrade (2004) e Barbêdo (2004).

Dando prosseguimento à reflexão teórica sobre o tema e visando analisar as tendências da literatura nacional a partir de 1997, apresentase, a seguir, uma nova revisão de literatura nacional contendo artigos técnicos, trabalhos apresentados em eventos científicos da área e dissertações e teses do campo ciência da informação e demais áreas relacionadas. Foram consultadas fontes oficiais e espera-se que o máximo de trabalhos tenham sido incluídos, com o objetivo de traçar o panorama pretendido. Além disso, foram incluídos, neste levantamento, alguns trabalhos publicados por autores nacionais em publicações internacionais, pois entende-se que, independente do canal de divulgação, essas obras representam a tendência da literatura nacional. Novamente, reitera-se que a intenção desta análise não é a de julgar a relevância ou qualidade dos trabalhos, mas, antes de tudo, estudá-los no contexto dos demais trabalhos, com a intenção de contribuir para o avanço dos estudos sobre administração de serviços de informação. É interessante destacar que, na revisão publicada em 1998, foram analisados dez trabalhos e, na 
presente revisão, sessenta e oito, considerando-se este um incremento expressivo. Entende-se que ele reflete a própria tendência da ciência da informação, que avançou muito nos últimos anos, principalmente nos temas relacionados à administração de serviços de informação, como reflexo do avanço das práticas gerenciais que, com todas as mudanças sociais e econômicas, também vem passando por rápidas e profundas alterações em todos os tipos de organizações.

Uma análise preliminar dos trabalhos demonstra algumas tendências ou enfoques na literatura nacional, que serão apresentadas a seguir, obedecendo a ordem cronológica de publicação dos trabalhos, dentro de cada bloco temático.

\section{Análises teóricas e práticas sobre a aplicação da gestão da qualidade em serviços de informação (abordagem genérica)}

Os principais autores destes enfoques são: Medeiros et al (2000), Vergueiro (2000), Silingovschi (200 I), Amboni (2002), Silva (2002), Vergueiro (2002), Longo e Vergueiro (2003), Amboni (2004), Nunes e Silva (2004) e Zanela (2005). Dois eixos se destacam: a modernização das práticas gerenciais e a liderança.

\section{a) modernização das práticas gerenciais}

A análise das tendências sobre a aplicação da gestão da qualidade em serviços de informação evidencia uma certa predisposição por parte dos dirigentes destes serviços em modernizar as práticas gerenciais utilizadas, buscando inclusive novas formas de organização do trabalho, muito mais focado no atendimento das necessidades dos usuários, em contraposição à disponibilização de documentos e informações de forma passiva. Não se trata, todavia, de um modismo sem fundamentação, mas de uma orientação para incorporar muitos anos de experiência das bibliotecas em atividades ligadas ao marketing, ao planejamento, à gestão por objetivos, ao controle de custos, à análise funcional etc. A gestão da qualidade, de forma geral, vem incorporando e reorientando todos estes componentes de maneira integrada, tendo como base a filosofia da melhoria contínua de cada processo implantado e uma orientação à satisfação do cliente (GÓMEZ HERNÁNDEZ, 2002, p. 65).

Além disso, este interesse pode ter sido motivado pela identificação de uma certa deficiência nos métodos de administração das bibliotecas brasileiras, traduzida em uma "carência de instrumentos gerenciais que permitam o levantamento e avaliação do desenvolvimento dos trabalhos e que possibilitem um controle maior da qualidade dos serviços prestados" (MEDEIROS et al, 2000, s.n.). Tradicionalmente, os serviços de informação vêm atuando como depositários de dados e informações e o grande avanço tecnológico das últimas décadas impulsionou a implantação de sistemas de informação que, de forma geral, agilizam a troca de informações e principalmente o acesso aos acervos. Recentemente, o interesse volta-se não somente aos serviços oferecidos em si, mas à qualidade percebida 
pelo cliente desses serviços e, principalmente, aos recursos utilizados para mantê-lo em pleno funcionamento (incluindo infra-estrutura, pessoal, equipamentos, acervo etc). A busca por novas práticas gerenciais e a preocupação com a melhoria dos serviços e produtos oferecidos, portanto, evidencia a gestão da qualidade como uma alternativa viável para ser estudada, adaptada e aplicada, como demonstram os vários relatos disponíveis nos trabalhos analisados. A qualidade, enquanto filosofia gerencial, tem a intenção de atenuar a diferença entre o que o Serviço de Informação oferece e o que, de fato, o cliente espera deste serviço (ABREU e ANDALIA, 1998, p. 80). Nesse sentido, como destacam Longo e Vergueiro:

Por suas características de adaptabilidade e transformação, a gestão da qualidade pode representar uma alternativa viável para que os serviços de informação ofereçam resposta apropriada às exigências de um novo tempo, considerando principalmente as características de um país em desenvolvimento e as implicações àqueles serviços situados na esfera da administração pública (2003, p. 40).

De forma geral, a opção dos serviços de informação pela gestão da qualidade pode ser resultado de vários fatores, como aponta Narcisa de Fátima Amboni:

a) da liderança, ou seja, esta deve ser autêntica em todos os níveis da biblioteca, assim como ter uma postura pró-ativa para facilitar a descoberta de novas oportunidades junto ao meio.

b) de um sistema de informações sobre qualidade em serviços. As bibliotecas precisam estabelecer um processo de pesquisa sobre a qualidade em serviços que forneça informações oportunas e importantes para subsidiar o processo de tomada de decisão.

c) da estratégia de serviços, com que os gestores podem avaliar o que deve ser aprovado e recusado. A estratégia serve como guia de orientação. Uma estratégia de serviços capta o que os usuários valorizam nos serviços prestados pelas bibliotecas.

d) do nível de comprometimento dos colaboradores internos e externos com os princípios da excelência em serviços. As bibliotecas como organizações prestadoras de serviços definem a sua razão de ser a partir da estratégia de serviços. A estratégia orienta e energiza a organização na criação de valor para os usuários.

e) de uma estratégia tecnológica na implementação da estratégia de serviços. A tecnologia é uma ferramenta básica à implementação da estratégia e para a qualidade dos serviços, em particular.

f) da estrutura e da tecnologia como fatores vitais à implementação da estratégia de serviços. Entretanto, as bibliotecas precisam de pessoas 
com atitudes, conhecimentos e habilidades necessárias para tornar a estratégia uma realidade.

g) dos níveis de confiabilidade, surpresa, recuperação e integridade, dentre outros fatores como por exemplo, cortesia, responsividade, acesso, credibilidade, rapidez de resposta, segurança, comunicação e competência que refletem as condições atuais das dimensões internas (liderança, propósitos, processos, acervo, pessoal, instalações físicas, orçamento e finanças e tecnologia), as externas diretas (usuários, fornecedores, concorrentes, grupos regulamentadores) e as externas indiretas (demografia, tecnologia, legal, política, social, econômica) existentes nas bibliotecas [...] $(2004$, s.n).

Neste cenário, os serviços de informação tendem a rever seu papel diante das Instituições mantenedoras (universidades, empresas privadas, fundações, institutos etc) que passam a exigir, no mínimo, alinhamento aos objetivos estratégicos, otimização de recursos e níveis de qualidade que justifiquem a própria manutenção do serviço. Adicionalmente, é necessária uma nova postura com os clientes direto (os usuários dos serviços) que assumem cada vez mais um papel ativo e exigente, fazendo parte do processo e posicionando-se, muitas vezes, de maneira crítica em relação a ele. Para que este reposicionamento tenha êxito, entretanto, é necessário que alguns paradigmas sejam quebrados. Talvez o mais importante esteja relacionado ao fato do profissional da informação, em geral, acreditar que conhece as necessidades dos clientes e que ele mesmo (o fornecedor de serviços) está apto a direcionar o planejamento e a execução dos produtos e serviços oferecidos, sem que seja dada ao cliente a chance sequer de se posicionar. Nesse sentido, "os profissionais da informação parecem entender que seus clientes não têm uma idéia muito clara daquilo que querem e nem condiçóes de avaliar corretamente o que recebem" (VERGUEIRO, 2002, p. 84).

\section{b) Lideranç̣a}

Obviamente, além da modernização das práticas gerenciais, os profissionais devem rever sua postura profissional, já que, na nova abordagem da prestação de serviços, os fornecedores são transferidos do papel de protagonistas para o de coadjuvantes, sem perder, obviamente, sua função e importância. Cabe, portanto, aos dirigentes dos serviços de informação, analisar sua própria equipe para identificar necessidades de treinamento e educação formal, além de proporcionar o desenvolvimento de novas habilidades e competências necessárias para o atendimento direto ao cliente, contribuindo para a elevação de seu nível de satisfação. A motivação e o alinhamento da equipe são vitais para a consecução dos objetivos relacionados à melhoria da qualidade, pois se torna de "extrema importância o comprometimento e o envolvimento de todos os níveis funcionais da organização, onde todos têm um papel a desempenhar, no esforço de garantir a qualidade 
nos serviços de informação" (SILINGOVSCHI, 200 I, s.n.). Dessa forma, acentua-se e se evidencia o papel da liderança, para que a gestão da qualidade possa ser entendida e de fato aplicada. A predisposição para a mudança, assim sendo, deve estar presente na liderança para que ela impulsione e encoraje sua equipe para as demais mudanças, por exemplo, no nível operacional, técnico e administrativo. Nesse sentido:

O sistema de liderança de uma biblioteca, que tem o compromisso com a qualidade em sua gestão, é o que promove o comprometimento profissional de seus colaboradores e possibilita a formação de um ambiente institucional propício ao desenvolvimento, concedendo autonomia decisória e construindo cadeias de comando leves e ágeis (com poucos níveis hierárquicos) (AMBONI, 2002, p. 176).

Através de uma liderança efetiva e de uma equipe capacitada e ciente do seu papel e de suas responsabilidades, o serviço de informação terá o ambiente mínimo necessário para implantar iniciativas ligadas à gestão da qualidade. Obviamente o entorno dessas iniciativas é muito maior e depende do ambiente externo da própria Instituição mantenedora, da provisão de recursos, do público ao qual se destina etc., sendo que cada serviço está inserido em uma cultura organizacional, com todos seus pontos favoráveis e desfavoráveis e cada caso deve ser analisado a partir desses pontos, utilizando-se, conseqüentemente, de estratégias eficazes e de um planejamento muito bem estruturado para que os projetos possam ser implantados, alcançando os objetivos pretendidos. Em contrapartida, existem também as dificuldades internas, as chamadas barreiras mentais e organizacionais que, certamente, serão encontradas durante a implantação de um processo de mudança originado da implantação da gestão da qualidade em serviços de informação, por exemplo: medo da mudança, apego excessivo a regras, descrença dos funcionários, burocracia, medo de perder poder e centralização das lideranças. Essas barreiras não podem ser subestimadas, devendo ser identificadas e, na medida do possível, transpostas para que o processo como um todo possa fluir conforme o planejado e os resultados possam ser obtidos. Como destacam Longo e Vergueiro a esse respeito:

Implantar com sucesso a gestão da qualidade em serviços de informação significa entender as barreiras e os conflitos gerados e aprender a gerenciá-los de forma eficiente e eficaz, procurando reduzir a ansiedade dos seres humanos e conduzindo-os a um processo de melhoria contínua. As pessoas têm que estar convencidas - e não ser obrigadas a acreditar -, que esse tipo de gestão implicará em vantagens pessoais (e para a organização) apreciáveis. Acima de tudo, essas vantagens são traduzidas em crescimento pessoal (2003, p. 53).

Logo, conclui-se que não existem fórmulas prontas e muito menos receitas pré-concebidas para que uma mudança desse porte e com tantas variáveis possa concretizar-se. Entretanto, considera-se que, 
uma vez definida a gestão da qualidade como o caminho a ser seguido, ela seja implantada de forma estruturada e, principalmente, mantendo o foco das atividades, tendo o apoio da alta direção e sendo constantemente avaliada, para que os objetivos possam ser alcançados da melhor forma possível, respeitando sempre a natureza e cultura do serviço de informação.

\section{Estudos e experiências práticas relacionadas especificamente ao estabelecimento de padrões de avaliação e indicadores da qualidade}

Os principais autores desta tendência são: Vergueiro e Belluzzo (1997), Vergueiro et al (1998), Vergueiro et al (1999), Linguanotto et al (2000), Vergueiro e Carvalho (2000a e 2000b), Vergueiro e Carvalho (200 I), Fonseca et al (2002), Ramos (2002), Sampaio et al (2002a e 2002b), Vergueiro e Carvalho (2002b), Andrade (2004), Fonseca et al (2004), Rebello (2004), Sampaio et al (2004b) e Rozados (2005a e 2005b).

Observamos, neste caso, que há um interesse particular por iniciativas ligadas ao estudo, estabelecimento e avaliação de padrões que possam identificar, concretamente, que os resultados estão sendo alcançados, especialmente os ligados à satisfação do cliente. Esta tendência está alinhada ao princípio da gestão da qualidade relacionado à tomada de decisões baseada em fatos, que coloca a administração de serviços de informação em um patamar contemporâneo, em que fatos concretos auxiliam o gerenciamento do serviço e o realinhamento de metas e atividades de acordo com os resultados efetivamente alcançados. Entende-se que o "estabelecimento de padrôes consistentes é condição essencial para implantação de um programa de garantia de qualidade em bibliotecas, cujos critérios de qualidade devem ser detectados e resolvidos mediante o estabelecimento de alvos" (RAMOS, 2002, s.n.). Da mesma forma, tem-se claro que alvos e metas concretas de desempenho devem ser estabelecidos e perseguidos como forma de aumentar a eficácia e eficiência dos serviços prestados; além disso, o estabelecimento de medidas de desempenho confiáveis pode auxiliar na avaliação dos serviços de informação de maneira isenta e baseada em métodos científicos. Nesse sentido,

Para que se obtenha a garantia da qualidade na implantação de um programa nas bibliotecas, é necessário que os bibliotecários desenvolvam padrões, medidas e indicadores dentro de suas unidades, tendo como alvo as necessidades dos usuários como também promovam a sensibilidade da equipe, implantando treinamento contínuo para que executem bem suas atividades técnicas rotineiras, utilizando-se adequadamente das estatísticas como parâmetros de avaliação para determinação de indicadores bons ou ruins, através da interação com seus clientes, transformando suas expectativas em medidas quantitativas e qualitativas (ANDRADE, 2004, p. 105). 
Adicionalmente, a pesquisadora Helen Beatriz Frota Rozados, em revisão de literatura realizada especificamente sobre indicadores aplicados à avaliação dos serviços de informação, afirma:

Percebe-se, em nível mundial, que o cada vez mais crescente incentivo pela busca da qualidade total nas unidades de informação, está fazendo com que aumente a preocupação com a definição e a utilização de indicadores apropriados, que auxiliem na avaliação e na gestão destes serviços. Os indicadores de desempenho, por medirem eficiência e eficácia, fatores que estão diretamente ligados à satisfação do usuário-cliente, têm sido os escolhidos por unanimidade, entre os autores e pesquisadores do tema. Concorda-se com esta escolha por se crer que o fim maior da gestão da qualidade é a satisfação do usuário-cliente e que a excelência desta satisfação só pode ser alcançada através de serviços eficientes e eficazes. Por outro lado, a busca pela excelência exige o sistemático levantamento de dados e informações, com a finalidade não somente de avaliar os serviços, mas, principalmente, utilizá-los como elementos do planejamento estratégico. Nesta perspectiva, entendem-se indicadores de desempenho como uma ferramenta para mensurar a satisfação do usuário e a qualidade dos serviços, com vistas à avaliação e à tomada de decisão (2005a, s.n).

Além dos trabalhos teóricos, destacam-se, neste enfoque, dois projetos bastante citados na literatura nacional:

a) Indicadores da qualidade em serviços de informação: validação em bibliotecas universitárias da área odontológica no Estado de São Paulo (USP, UNESP e UNICAMP). Este projeto representa uma pesquisa inovadora na área e colabora para que a definição de indicadores possa constituir-se em estratégia viável visando à qualidade de processos e serviços nos serviços de informação de países em desenvolvimento. Divulgado em: Vergueiro e Belluzzo (1997), Vergueiro et al (1998), Vergueiro et al (1999), Vergueiro e Carvalho (2000a e 2000b), Vergueiro e Carvalho (200 I ) e Vergueiro e Carvalho (2002b).

b) Estudos iniciais e relato da implantação de um programa de avaliação da qualidade - PAQ - nas bibliotecas universitárias do SIBI / USP. O PAQ apresentou-se como elemento de aproximação entre o usuário e as bibliotecas, além de ser viável e necessário para a gestão das bibliotecas do sistema. Divulgado em: Linguanotto et al(2000), Sampaio et al(2002a 2002b), Rebello (2004) e Sampaio et al (2004b). 


\section{Iniciativas ligadas ao estudo do cliente e ao estabelecimento de produtos e serviços segundo sua ótica}

Principais autores: Baptista (2000), Vergueiro (2000a, 2000d e 2000c), Xavier (200 I ), Martins et al(2002), Igami et al(2004) e Salasário (2004).

Como não poderia deixar de ser, nesta tendência observam-se trabalhos relacionados ao estudo do cliente, o que é bastante natural, uma vez que a gestão da qualidade tem este foco. Contudo, o relevante na literatura estudada é o destaque para a ótica do cliente, ou seja, esperase entender e captar as suas reais expectativas, buscando atendê-las e, antes de tudo, entendê-las. Torna-se importante registrar que o estudo de usuários é uma linha de pesquisa clássica na área da ciência da informação, porém, o que pode ser ressaltado nos trabalhos citados é a premissa de que ninguém melhor do que o próprio cliente para definir suas necessidades e o nível de qualidade do serviço recebido:

É fundamental, na qualidade em serviços, sua dimensão técnica (produtos ou resultados do serviço - $\bigcirc$ QUE) e a dimensão funcional do processo (COMO o serviço é entregue), bem como a compreensão da relação fundamental entre oque é a qualidade esperada (expectativas do cliente) versus a qualidade experimentada (percebida pelo cliente) (MARTINS et al, 2002, s.n.).

Um estudo interessante foi desenvolvido e divulgado em Vergueiro (2000a, 2000c e 2000d) em que o autor exemplifica, através de estudos de casos fictícios, situações em que a opinião do profissional da informação diverge da opinião do cliente, ou seja, o fornecedor tem plena convicção de ter desempenhado bem o seu papel, porém esta não é a opinião de quem recebe o serviço. Esta contradição é muito elucidativa, pois resume a idéia da qualidade percebida, que depende muito mais de elementos subjetivos do que se pode imaginar:

Uma forma um pouco mais natural de inserir a preocupação com os clientes nos serviços é, talvez, identificar casos em que a visão que eles possuem sobre a qualidade do serviço e aquela possuída pelos bibliotecários mostram-se nitidamente discordantes, causando algum tipo de diferença de opinião entre eles (muitas vezes, até mesmo um choque de personalidades). Tradicionalmente, os profissionais da informação, tanto os de bibliotecas universitárias como os de outros tipos de bibliotecas, experimentam situações diversas que envolvem relações de conflito ou desconforto com seus clientes. Dependendo da situação, essas relações podem ser bem ou mal resolvidas, mas sempre deixam como resultado um impacto negativo sobre o serviço que às vezes leva anos para ser totalmente absorvido (VERGUEIRO, 2000d, p. 52). 
Um outro aspecto desta análise é que não basta conhecer o que o cliente quer, mas principalmente poder oferecer o que ele precisa. Sabemos que os serviços de informação, de uma maneira geral, têm avançado muito nas últimas décadas em vários aspectos, porém, existem serviços com insuficiência de recursos básicos, como por exemplo, mãode-obra e, neste caso, toda a base teórica disponível não tem espaço para sua aplicação. Além desse aspecto, a "melhor maneira de proporcionar um atendimento de qualidade é conhecendo bem o usuário, conhecendo o propósito da Instituição e os produtos e serviços que se está oferecendo" (BAPTISTA, 2000, s.n.). Outro estudo de destaque nesta linha foi o desenvolvido por Xavier (200 I), que estudou estratégias de serviço voltadas à satisfação do cliente, realizando um contraponto entre a teoria e a prática, através de pesquisa realizada em Bibliotecas Universitárias das Universidades Estaduais Paulistas. Nesse sentido,

embora uma biblioteca possa operar continuamente em um nível aceitável de qualidade, a sobrevivência e validação do seu desempenho dentro da Instituição dependerá, fortemente, do grau de qualidade que os seus usuários the atribuem (IGAMI et al, 2004, s.n).

\section{Uso de ferramentas e metodologias relacionadas a conceitos e fundamentos da gestão da qualidade em serviços de informação}

As principais ferramentas ou conceitos desta tendência da literatura especializada no período, com seus respectivos autores, são: QFD: Ferreira (1997) e Barbêdo et al(2003); 5S - Vanti (1999) e Ferreira (2002); Benchmarking - Suaiden e Araújo Júnior (200l), Empreendedorismo e Gestão da Qualidade - Gomes Filho e Honesko (2004); Endomarketing e 5S - Bonetti e Machado (2005) e Rebello (2005); Momentos da verdade e outras técnicas - Gomes Filho (200 I e 2002); Objetivos organizacionais - Silva (2000b); Teoria de Garvin Barbêdo e Turrioni (2003b); Teoria de Deming - Pinheiro e Costa (2000).

Especificamente em relação ao uso de técnicas, ferramentas ou metodologias para o aprimoramento dos serviços de informação, foram identificados vários relatos eminentemente práticos; entretanto, é necessário destacar que, comparados com a revisão de literatura publicada em 1998, os estudos posteriores, em alguns casos, foram pioneiros e até mesmo ousados, por absorver conceitos da engenharia da produção à realidade dos serviços de informação, com forte fundamentação teórica e, principalmente, com um enfoque prático através das validações realizadas em organizações prestadoras de serviços de informação. Destacam-se, neste comentário, os trabalhos de Vanti ( | 999), Barbêdo et al (2003), Suaiden e Araújo Júnior (200 I ), Barbêdo e Turrioni (2003b) e Gomes Filho e Honesko (2004). Estes trabalhos, em conjunto com os demais citados e analisados anteriormente, decididamente contribuíram para $\circ$ avanço da base 
teórica em relação aos estudos sobre a aplicação de gestão da qualidade em serviços de informação, de maneira fundamentada e com alto grau de rigor técnico, o que colaborou de forma irrefutável para o avanço da ciência da informação.

\section{Estudo da teoria de processos e sua aplicação em serviços de informação}

Destacam-se os trabalhos de Santos (2000), Silva (2000a), Santos et al (2003), Reis e Blattmann (2004) e Valls (2004).

A partir de 2000 podemos identificar uma nova linha de pesquisa nos estudos publicados, relacionada à análise da teoria de processos e sua aplicação em serviços de informação. Destaca-se o trabalho publicado por Silva (2000a) que não é diretamente relacionado à gestão da qualidade, mas que pode ser considerado como introdutório ao tema em razão de sua excelente revisão de literatura e apresentação didática. A autora realiza uma revisão histórica das formas de organização do trabalho, do taylorismo aos dias atuais, contextualizando os serviços de informação neste sentido, que contribui para introduzir um tema que vem sendo abordado por outros pesquisadores da ciência da informação, analisando as características e facetas da prestação de serviços de informação, conforme salientam SANTOS et al:

setor de prestação de serviços tem crescido continuamente na economia mundial. Diante dessa situação, a comunidade acadêmica e os profissionais das diversas áreas do conhecimento começaram a voltar suas atenções para as particularidades da gestão de serviços. A busca de melhoria da qualidade, tão comum em empresas industriais, passou a ser prioridade também nas organizações prestadoras de serviços. Assim, a gestão de processos passa a ter papel crucial nas organizações de serviços, principalmente para as organizações voltadas à prestação de serviços de informação, como no caso das bibliotecas (2003, p. 85).

A análise sistemática das organizações, advinda da teoria de processos, prevê uma nova forma de enxergar as atividades em operação destacando a eficiência do processo, ou seja, como a atividade é realizada ao longo de todas as etapas, não somente o resultado final do produto ou serviço, que pode ter sido oneroso em vários aspectos. Essa análise sustenta a otimização dos processos que podem ser gerenciados de maneira integrada, compartilhando os recursos, principalmente os humanos e tecnológicos, além do próprio mapeamento de seu impacto no resultado final dos serviços prestados (VALLS, 2004). Trata-se de abordagem perfeitamente aplicável aos serviços de informação e a literatura analisada destaca que os processos devem ser o centro das atenções dos dirigentes desses serviços: 
Os processos precisam ser detalhadamente estudados e projetados, verificar o que é imprescindível e, acima de tudo, precisam ser compreendidos por todos para haver uma visão geral e profunda do que está acontecendo e em benefício de quem (REIS e BLATTMANN, 2004, p. 15).

Adicionalmente, a literatura analisada apresenta relatos sobre a análise de técnicas e metodologias para que este estudo possa ser realizado, como divulgado em Santos (2000) e Santos et al (2003).

\section{Certificação de serviços de informação segundo padrões estabelecidos.}

Destacam-se os seguintes trabalhos: Barbalho (1997), Vergueiro e Carvalho (2002a), Barbêdo e Turrioni (2003a), Vergueiro e Carvalho (2003), Barbêdo (2004), Martins e Lotti (2004), Saad et al (2004), Valls (2005) e Walter (2006).

A certificação de sistemas de gestão da qualidade implantados direta ou indiretamente em serviços de informação é um aspecto da preocupação com a qualidade que apresenta evidente avanço no Brasil, ainda que modesto. Um dos primeiros trabalhos relacionados a este tema foi o estudo de Célia Regina Barbalho (1997) sobre a aplicação do modelo inglês de certificação (National Health Service) em serviços de informação. Segundo a autora, em razão de sua característica de prestação de serviços, os serviços de informação possuem um caráter próprio, o que implica uma relação complexa com seus clientes, uma vez que os serviços de informação são intangíveis, heterogêneos e simultâneos, o que favorece a necessidade de implantação de um modelo de gestão da qualidade (lbid., p. 53).

Especificamente sobre a certificação de serviços de informação, foi realizada uma pesquisa que procurou verificar a utilização de programas de qualidade nas bibliotecas universitárias brasileiras, para identificar as instituições envolvidas em processos de busca de qualidade, em um primeiro momento, com base no modelo NBR ISO 9000 e, em seguida, em razão do insucesso na localização de serviços de informação certificados com base na NBR ISO 900 I, direcionando o estudo para os prêmios de qualidade nacionais sob o ponto de vista de sua aplicação como passo inicial para a certificação da qualidade em bibliotecas universitárias. Essa pesquisa foi divulgada em Vergueiro e Carvalho (2002a e 2003). Segundo os autores, a certificação de serviços de informação, especificamente de bibliotecas universitárias, encontrava-se em fase embrionária, porém, independente deste fato, a "busca da certificação configura-se como uma alternativa possível, desde que as gerências, equipes e, principalmente, as instituiçôes mantenedoras das bibliotecas universitárias estejam engajadas no processo" (/d., 2002a, s.n).

É importante registrar que os primeiros serviços de informação 
brasileiros certificados com base na NBR ISO 900 I datam do final de 2002 e a literatura especializada começa a abordar esta tendência, inicialmente com a dissertação de mestrado cujo estudo de caso foi realizado na primeira biblioteca certificada no Brasil, a Biblioteca Mário Henrique Simonsen, da Fundação Getúlio Vargas, no Rio de Janeiro (BARBÊDO; TURRIONI, 2003a, e BARBÊDO, 2004). Uma outra implantação pioneira, a da Biblioteca Ministro Victor Nunes Leal, do Supremo Tribunal Federal, foi relatada em detalhes, apresentando um panorama sobre a implantação da ISO 900 I:2000 em um serviço de informação, registrada em Walter (2006). Complementando esta abordagem, vários estudos teóricos foram divulgados, com destaque para os de Martins e Lotti (2004) e Valls (2005), este último resultado de vasta pesquisa realizada para elaboração de tese de doutorado, cujo tema principal foi a aplicação da gestão da qualidade em serviços de informação no Brasil. Uma outra experiência prática de destaque é relatada em Saad et al(2004), que descreve a experiência da Divisão de Biblioteca e Documentação -DIBD-, da Escola Superior de Agricultura Luiz de Queiroz -ESALQ-, da Universidade de São Paulo na aplicação do modelo de gestão proposto segundo os critérios do Prêmio Paulista de Qualidade de Gestão -PPGQ-. A experiência da DIBD é muito relevante, pois este serviço de informação, em razão de sua excelência, foi agraciado com a medalha de bronze no PPGQ de 2003, fato que comprova a aplicabilidade e principalmente a importância da modernização das práticas de gestão em serviços de informação brasileiros.

\section{Abordagens especificas}

Destacam-se neste tema os trabalhos sobre: Auditoria interna Moretti e Pereira Júnior (2004); Capacitação em qualidade - Sampaio et al (2004a); Gestão de pessoas - Castro Filho e Vergueiro (2004); Participação do profissional da informação em sistemas da qualidade Valls (1998) e Psicologia organizacional - Delpizzo (2005).

Todos esses trabalhos evidenciam o avanço do tema, que, especificamente a partir de 2000, reflete o avanço da aplicação deste modelo de gestão nas organizações ligadas ao gerenciamento de informação. $\bigcirc$ avanço da gestão da qualidade nos serviços de informação parece ter motivado os dirigentes destes serviços e os pesquisadores a se aprofundarem em assuntos relacionados, cuja importância tem sido destacada na literatura analisada. Também se destaca um estudo anterior, relacionado especificamente a participação dos profissionais da informação nos sistemas da qualidade (VALLS, 1998), dissertação de mestrado que analisou um novo espaço de atuação para esses profissionais, principalmente nos serviços de informação especializados inseridos em organizações já envolvidas em programas formais relacionados à gestão da qualidade. 


\section{Considerações finais}

Concluindo a revisão de literatura nacional, podemos citar, além das questões temáticas já abordadas, outros fatos relevantes:

- dos trabalhos analisados, cerca de 50\% representam experiências eminentemente teóricas, o que altera favoravelmente o panorama da revisão publicada em 1998, em que a abordagem era quase que exclusivamente prática. É óbvio que o enfoque pragmático é muito importante para o avanço do tema, mas se entende que a proliferação de estudos teóricos fundamenta o tema na literatura nacional, que avança do estágio exploratório para um estágio de maturidade em que há uma diversificação de pontos de vista e de abordagens;

- $\quad$ em relação ao tipo de serviço de informação analisado, os estudos se concentram quase que exclusivamente em bibliotecas universitárias (mais de $70 \%$ dos trabalhos). Nota-se que estudos referentes a serviços de informação ligados a Instituições privadas, fundações ou órgãos públicos são praticamente nulos. Esse fato pode ser considerado contraditório, pois a grande ocorrência de certificações com base na NBR ISO 900 I e outros programas ligados à gestão da qualidade pode ser observada em empresas de caráter privado e, neste caso, seus serviços de informação não estão sendo envolvidos, pelo menos na literatura especializada nacional;

- diferente do panorama de 1998, que destacou a ocorrência de iniciativas isoladas sem fundamentação teórica, considera-se que a literatura nacional evoluiu muito no período pós- 1998, principalmente pela ocorrência de estudos acadêmicos desenvolvidos na área de ciência da informação e de engenharia de produção.

Entende-se, portanto, que os estudos referentes à aplicação da gestão da qualidade em serviços de informação no Brasil têm se mostrado em crescente evolução, dos primeiros trabalhos publicados até os dias atuais, como pode ser observado na literatura analisada. Espera-se que a presente revisão de literatura possa, de forma direta, apoiar outros pesquisadores do tema, engrandecendo desta forma este tema na literatura nacional e oportunizando sua aplicação prática em serviços de informação.

\section{Quality management in information services in Brazil: a new literature revision from 1997 to 2006}

Describes the implementation of the Quality Management in Information Services in Brazil through national literature revision aiming at the revision complementation of the literature published in 1998. This work also presents a new panorama introducing works published since 1997 in an effort to contribute to the progress of discussions related to the application of the Quality Management in Information Services in Brazil, and add a new theoretical approach to the subject.

Key-words: Quality management; Information services 


\section{Referênclias}

AMBONII, Narcisa de Fátima. Qualididade eml servị̣cos: dimensõos para orientaçãa e avaliação das bibliotecas universitárias federais brasileiras. 2002, 227 f. Tese (Doutorado em Engenharia de Produção) - Centro Tecnológico da Universidade Federal de Santa Catarina, Florianópolis, 2002. Disponível em: $<$ http://teses.eps.uffc.br/Resumo.asp?3802 > .Acesso 19 out. 2004.

Qualidiade em serviços: dimensões para orientação e avaliação das bibliotecas universitárias federais brasileiras. In: SEMINÁRIO NACIONAL DE BIBLIOTECAS UNIIERSITÁRiIAS, 13., 2004, Natal. Anais... Natal: BCZZM, 2004.

AMDRADE, Marcos Vinícius Mendonça. Gestão da qualiddade em bibliotecas universitárias: indicadores de desempenho e padrões de qualidade. 2004,115 f. Dissertaçãão (Mestrado em Sistemas de Gestão) - Universidade Federal Fluminense, Niterói, 2004.

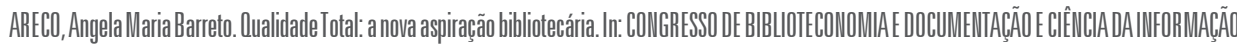

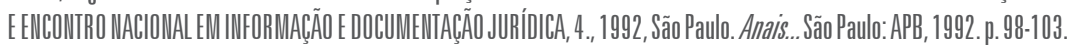

BAPIISTA, Ivani. Diagnóstico do nível de satisfação do cliente da biblioteca central da Universiddade Estadual de Maringá com vistas à qualidade. In: SEMINÁRIIO NACLONAL DE BIBLLOTECAS UNIVERSITÁRIIAS, 11., 2000, Florianópolis. Anais... Florianópolis: UFSC, 2000. Não paginado. Disponivel em: < hittp: /snbu.bus.br/snbu2000/docs/p/doc/poster014.doc > . Acesso 4 out. 2004.

BARBALHO, Célia Regina Simonetti. Gestão pela qualidade: referencial teórico. Iranssinformação, Campinas, v. 8, n. 3, p. 97-120, set./dez. 1996. .Padrão de conformidade para Unidades de Informação: apresentaçãa do modelo inglểs. Informaçãa đ Informacãão, Londrina, v. 2, n. 2, p. 47 . 54, jul./dez. 1997 .

Qualidade đ Unidades de informaçãa: uma parceria em busca de melhoria. 1995, 133 f. Dissertaçãa (Mestrado em Biblioteconomia) -

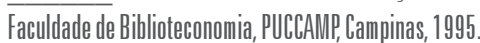

BARBỄo, Simone Angélica Del-Ducca. Sistemlad de gestão da qualidade emll servị̣cos: estudo de caso em uma biblioteca universitária. 2004, 134 f. Dissertação

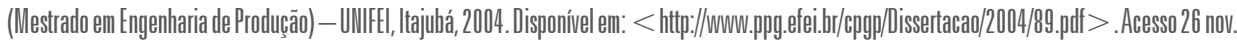
2004.

BARBêDo, Simone Angélica Del-Ducca et al. Avaliação dos serviços e identificaação de oportunidades através do Desdobramento da Funcão Qualidade.

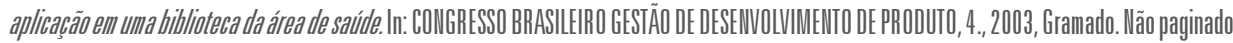
Disponivel em: $<$ http://www.iem.efei.br/sanches/Pesquisa//Aritigos\%20publicados/a40.PDF > . Acesso 7 dez. 2004.

BARBÊDO, Simone Angélica Del-Ducca; TURRIOWI,João Batista. Sistema de Gestão da Qualidade e um modelo de integração estrutural em bibliotecas: análise

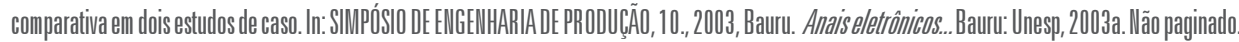
Disponivel em: < http://www.simpep.feb.unesp.br/anais10/gestaoqualidprodutividade/arg01.PDF > Acesso 24 nov. 2004.

Sistemas de gestão da qualidade no setor de serviços. um estudo de aplicabilidade em bibliotecas de ensino superior de uma cidade mineira.

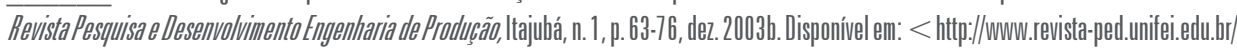
nl_art05.pdf > Acesso 4 out.2004.

BELLUZZO, Regina Célia Baptista; MACEDo, Neusa Dias de. A gestão da qualidade em serviços de informação: contribuição para uma base teórica. Ciềncia da Informação, Brasilia, v. 22, n. 2, p. 124-32, maio/ago. 1993.

BONETTI, Thiago Medeiros; MACHADO, Cristiane Salvan. A gestão da qualidade aplicada às bibliotecas universitárias da Universiddade do Sul de Santa Catarina

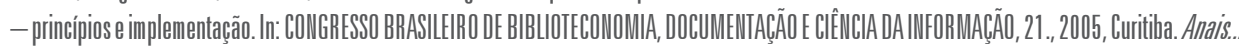
Curitiba: FEBAB, 2005. s.n.

CASTRO FILHO, Cláudio Marcondes de; VERGUEElRO, Waldomiro. Gestão de pessoas em bibliotecas universitárias sob a ótica das teorias da qualidade: reflexões sobre a realidade brasileira. In: SEMINÁRIIO NACLONAL DE BIBLIOTECAS UNIVERSITÁRIAS, 13., 2004, Natal. Anais... Natal: BCZM, 2004. s.n.

DELPIZZO, Cynthia Esteves et a/. A psicologia organizacional como facilitadora do processo de implantação do programa de Gestão da Qualidade nas

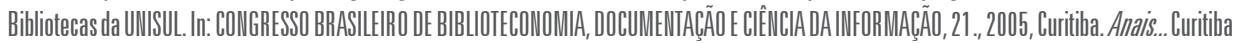
FЕВАВ, 2005. s.ก.

FERREIRA, Angela de Moura. Desdobramento da qualidade eml servigcos.o caso da biblioteca da Escola de Engenharia da UFFGS. 1997, 171 f. Dissertação (Mestrado em Engenharia de Produção) - Universidade Federal do Rio Grande do Sul, Porto Alegre. 1997. Disponivel em: < hittp://wwww.producao.ufrugs.br/ banco_Teses/detalhes_trab.asp? cod_trabalho $=216$ frordem $=\mathrm{t} \%$ [3\%ADtulo $>$.Acesso em 7 dez. 2004. 
FERREIRA, Danielle Thiago. O ambiente de qualidade em um sistema de informação e a aplicação do programa 5s. In: SEMINARIO NACIONAL DE BIBLLOTECAS UNIVERSITÁRIASS, 12., 2002, Recife. Anais... Recife: Universidade Federal de Pernambuco, 2002. Disponivel em: < hittp://libdigi.unicamp.br/document/ ? code $=1194>$. Acesso 21 dez. 2004.

FONSECA, Nadia Lobo da et alAplicação da metodologia de indicadores de qualidade para planejamento da gestão em bibliotecas universitárias da UERJ. In: SEMINÁRIIO NACIONAL DE BIBLIOTECAS UNIVERSITÁRIIAS, 13., 2004, Natal. Anais... Natal: BCZM, 2004.13p.

Desenvolvimento de indicadores de qualidade para o planejamento da gestão em unidades de informação da Rede SIRIUS - Rede de Bibliotecas UERJ. In: SEMINÁRIIO NACLIONAL DE BIBLLOTECAS UNIVERSITÁRIASS, 12., 2002, Recife. Anais... Recife:UFPE, 2002. Não paginado. Disponivel em: $<$ hitp.//www.sibi.ufrj.br/snhu/snbu2002/oralpdt/114.a.pdf > .Acesso 4 out.2004.

GOMES FHLHO, Antônio Costa. Qualidade: momentos da verdade no serviço de atendimento aos usuários. 2001. 137 f . Dissertação (Mestrado em Biblioteconomia) - Pontifícia Universiddade Católica de Campinas. Campinas, 2001.

.Qualidade: momentos da verdade no serviço de atendimento aos usuários. In: SEMINÁRIO NACIONAL DE BIBLIOTECAS UNIVERSITÁRIIAS, 12. 2002, Reciffe. Anais...Recife:UFPE, 2002.15p.Disponível em: < htttp://www.sibi.ufrj.br/snbu/snhu2002/oralpdt/18.a.pdf > . Acesso 4 out.2004.

GOMES FILHO, Antônio Costa; HONESKO, Astrid. Qualidade e empreendedorismo em Unidades de Informaçãa: uma proposta integrada. Guarapuava: Ed. UNCENTRO, 2004.117p.

IGAMI, Mery P.Zamudio et a/.0 uso do SERVQUAL na verificação da qualidade dos serviç̧os de unidades de informação: o caso da biblioteca do IPEN. In: SEMINÁRIO NACIONAL DE BIBLLOTECAS UNIVERSIIÁRIAS, 13., 2004, Ilatal. Anais... Natal: BCZZM, 2004. s.n.

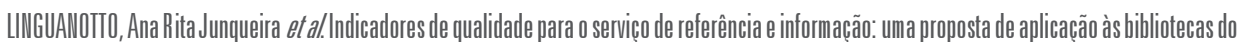
SIBI/USP. In: SEMINÁRIIO NACIONAL DE BBBLLOTECAS UNIVERSIIÁRIAS, 11., 2000, Florianópolis. Anais... Florianópolis: UFSC, 2000.21 p.

LONGO, Rose Mary Juliano, VERGUEEIRO, Waldomiro. Gestão da Qualidade em Serviççs de Informação do setor público: caracteriśticas e dificuldades para sua aplicação. Revista Digital de Biblioteconomia e Ciência da Informação, Campinas, v. 1, n. 1, p. 39-59, jul./dez. 2003. Disponivel em: < http:// server01.bc.unicamp.br//revbib/artigos/art_4.pdf>.Acesso 4 out.2004.

MARIIIISS, Neire do Rossio et al.Avaliação da qualidade de um serviçço do sistema de arquivos da Unicamp: um modelo piloto de pesquisa com os usuários. In: CONGRESSO INTER MACIONAL DE ARQUUUOS BibLLOTECAS CENTROS DE DOCUNENTAÇ̃̃O E MUSEUS, 1., 2002, São Paulo. Textos...São Paulo: Imprensa Oficial, 2002.p. 277-93.Disponível em: < http://wwww.unicamp.br//siarr/publicacoes/artigo_integrar_neire.pdf > .Acesso 4 out. 2004.

MARTIINS, Valéria dos Santos Gouveia; LOTII, Luciane Politi. Guia para implantą̧ão da norma NBR ISO 9001:2000 em Bibliotecas. In. SEMIINÁRIIO NACIONAL DE BIBLIOTECAS UNIVERSITÁRIIAS, 13., 2004, Ilatal. Anais... Natal: bCZM, 2004. s.n.

MEDELROS, Ana Lígia S. et a/Qualidade e produtividade em bibliotecas: estudo de caso da Biblioteca Mário Henrique Simonsen. In: SEMINÁRIO NACIONAL DE BIBLIOTECAS UNIVERSITÁRIAS, 11., 2000, Florianópolis. Anais... Florianópolis: UFSC, 2000. Não paginado. Disponível em: $<$ www.bibliotestudantes.hpg.ig.com.br/texto-91.pdf>. Acesso 20 dez.2004.

MORETTI, Adriana Bueno; PEREIRA JÚWIOR, Geraldo. Auditoria interna do Sistema de Gestão pela Qualidade. In: SEMINÁRIO NACIONAL DE BIBLIOTECAS UNIVERSITÁRIIAS, 13., 2004, Natal. Anais... Natal: BCZM, 2004. s.n.

NUNES, Vera Vilene Ferreira; SIlLA, Gisélia Ferreira da. Estratégias de ação para gestão da qualidade nos serviços informacionais do sistema de bibliotecas da Universidade Estadual de Feira de Santana. un estudo de caso. In: SEMINÁRi IO NACIONAL DE BIBLLOTECAS UNIVERSIIÁRiIAS, 13., 2004, Natal. Anais... Natal: BCZMI, 2004. s.n.

PINHEIRO, Edna Gomes; COSTA, Maria de Fátima Oliveira. Qualidade Iotal em Bibliotecas Universitárias a filosofia de Deming e a Biblioteca Universitária: uma nova relação em busca da gestão da qualidade. Biblioteca Universitária, maio 2000. Não paginado. Disponível em: < http://wwww.biblioteca.uff.brr/ artqualidad.html> . Acesso 4 out. 2004.

PINTO, Virgínia Bentes. Informação: a chave para a qualidade total. Ciềncia da Informação, Braśilia, v. 22, n. 2, p. 133-7, maio/ago. 1993.

RAMOS, Maria Etelvina Madalozzo. Padrões como instrumento de avaliação da qualidade em bibliotecas universitárias. In: SEMINARIO NACLONAL DE BIBLIOTECAS UNIVERSITÁRIASS, 12., 2002, Recife. Anais... Recife: Universidade Federal de Pernambuco, 2002.Disponivel em: < hittp://Wwww.sibi.ufrj.br/snbu/ snbu2002/oralpdt/94.a.pdf>. Acesso 21 dez. 2004.

REBELLO, Maria Alice de França Rangel. Avaliação da qualidade dos produttos/serviços de informação: uma experiência da Biblioteca do Hospital Universitário da Universidade de São Paulo. Revista Digitalde Biblioteconomia e Ciênncia da Informacãa, Campinas, v. 2, n. 1, p. 80-100, jul./dez. 2004. Disponível em:

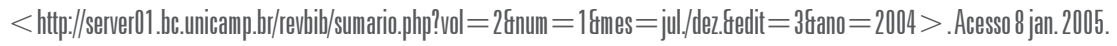


Implantação do Programa 5 S para a conquista de um ambiente de qualidade na Biblioteca do Hospital Universitário da Universidade de São Paulo. Revista Digital de Biblioteconomira e Ciência da Informação, Campinas, v. 3, n. 1, p. 165-182, jul./dez. 2005. Disponível em: < http:/l server01.bc.unicamp.br/ser/ojs/viewarticle.php? ?id=54flayout = abstract $>$. Acesso 8 fev. 2006.

REIS, Margarida Maria de Oliveira; BLATTMANW, Ursula. Gestão de processos em bibliotecas. Revista Digitalde Biblioteconomia e Ciênncia da Informacãoa, Campinas, v. 1, n. 2, p.1-17.jan./jun. 2004. Disponivel em: < hittp://server01.bc.unicamp.br/revbib/artigos/art 6.jdf > . Acesso 4 out. 2004.

ROCHA, Eliana da Conceição; GOMES, Suely Henrique de A. Gestão da qualidade en unidades de informação. Ciềncia da Informação, Brasilia, v. 22, n. 2 p. 142-52, maio/ago. 1993

ROCHA FlLHO, José Queiroz da. Qualidade total em serviços de informação: o caso da siderúrgica nacional. In: INFOIMAGEM, 1995, São Paulo. Anais... São Paullo: CENADEM, 1995.

ROZADOS, Helen Beatriz Frota. Indicadores como ferramenta para avaliação de Serviços de Informação. In: CONGRESSO BRASILEIRO DE BIBLIOTECONOMIA,

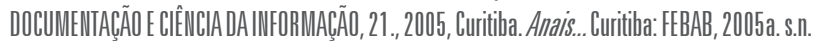

.Uso de indicadores na gestão de recursos de informação. Revista Digital de Biblioteconomia e Ciềncia da Informacãa, Campinas, v. 3, n. 1 ,

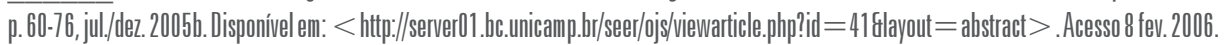

SAAD, Márcia Regina Migliorato et al. A DIBD e sua trajetória na conquista do Prêmio Paulista de Qualidade de Gestão. In: SEMINÁRIO NACIONAL DE BIBLIOTECAS UNIVERSITÁRIAS, 13., 2004, Natal. Anais... Natal: BCZZM, 2004. s.n.

SALASÁR IO, Maria Guilhermina Cunha. Metodolog̣ia de implantação e avaliação da qualidade de bibliotecas universitárias especializadas através da ótica dos usuários / clientes: o caso dos 4 A. In: SEMINÁRIO NACIONAL DE BIBLIOTECAS UNIVERSITÁRIAS, 13., 2004, Natal. Anais... Natal: BCZZM, 2004. s.n.

SAMPAIO, Maria Imaculada Cardoso et al. Avaliação continuada da qualidade dos produtos e serviços oferecidos pelo SIBI//USP. In: SEMINÁRIO NACIONAL DE BIBLIOTECAS UNIVERSIIÁRIAS, 12., 2002, Recife. Anais... Recife: UFPE, 2002a. Ião paginado. Disponivel em: < http://wwww.sibi.ufrj.br/snbu/snbu2002/ oralpdt/98.a.pdf > . Acesso 4 out.2004.

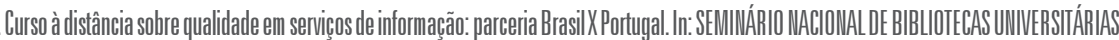
13., 2004, Natal. Anais... Natal: BCZZM, 2004a. s.n.

PAQ - Programa de avaliação da qualidade de produtos e serviços de informação: uma experiência no SIBi/USP. Ciênncia da Informacãõ,

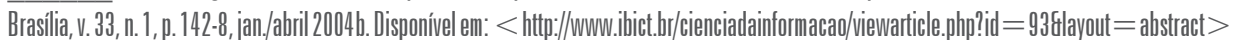
Acesso 4 out. 2004

Percepção do cliente em relaçãa à qualidade dos produtos e serviços oferecidos pelo SIBI/USP. In: SEMINÁRIO NACIONAL DE BIBLLOTECAS

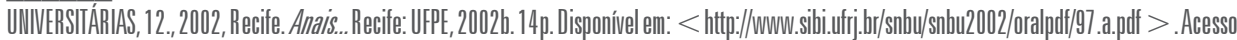
17 out. 2004.

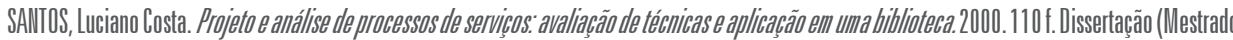
em Engenharia de Produção) - Universiddade Federal de Santa Catarina, Florianópolis, 2000. Disponivel em: < httpp://www.lgti.ufsc.br/public/luciano.pdf > Acesso 6 out. 2004

SANTOS, Luciano Costa et al. Gerenciando processos de serviços em bibliotecas. Ciềncia da Informacãa, Brasilia, v. 32, n. 2, maio/agyo, 2003, p. 85-94 Disponivel em: $<$ http://www.bict.br/cienciadainformacao/viewarticle.php?id = 1554layout=abstract $>$. Acesso em 4 out. 2004 .

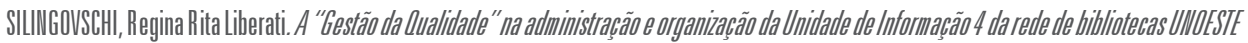
de Presidente Prudente. UEL, 2001. Não paginado. Disponivel em: < hittp://wwww.biblioestudantes.hpg.ig.com.br/129.doc > . Acesso 24 nov. 2004.

SILUA, Ana Estela Codato. Gestão da Qualidade em Bibliotecas: aspectos criticos. In: SEMINÁRIO NACLONAL DE BIBLIOTECAS UNIVERSITÁRIAS, 12., 2002, Recif́e. Anais... Recife: UFPE, 2002.14p. Disponivel em: < http.//wwww.sibi.ufrj.br/snbu/snbu2002/oralpdt/12.a.pdf> . Acesso 4 out. 2004.

.Organização do processo de trabalho em bibliotecas. In: SEMINÁRIIO NACIONAL DE BIBLIOTECAS UNIVERSITÁRIIAS, 11., 2000a, Florianópolis. Anais... Florianópolis: UFSC, 2000. 11p. Disponivel eml: < http://snbu.bus.br//snbu2000/docs/pt/doc/t016.doc > . Acesso 24 nov. 2004.

SIIUA, Antônio Manoel dos Santos et al. O plano de Gestão da Qualidade e sua implantacão na Rede de Bibliotecas da UNIILSP: relato de unma experiênncia. São Paullo: APB, 1995. (Ensaios APB, n. 24).

SILVA, Sueli Maria Goulart. Qualidade nas bibliotecas universitárias: a influência dos objetivos. Informação e Sociedade: Estudos, João Pessoa, v. 10, n. 1,

2000b, p.54-69. Disponivel em: < hittp://wwww.informacaoesociedade.ufph.br/1010003.html > . Acesso 4 out. 2004. 
SUAIDEN, Emir José, ARAÚJO JÚNIOR, Rogério Henrique. Biblioteca pública e a excelência nos produtos e serviços: a técnica do benchmarking. Informą̧ãa e Socieddade: Estuddos,João Pessoa, v. 11, n. 1, 2001, p.15-34. Disponivel em: < hittp.//wwww.informacaoesociedade.ufph.br/1110101.pdf > Acesso 4 out. 2004.

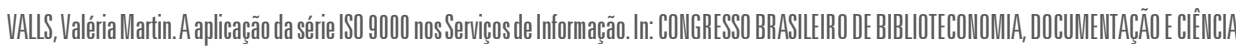
DA INFORMAÇÃ0, 21., 2005, Curitiba. Anais... Curitiba: FEBAB, 2005. s.n.

.0 enfoque por processos da WBR ISO 9001 e sua aplicação nos serviços de informação. Ciência da Informalção, Braślia, v. 33, n. 2, p. 172 . 8, maio/ago. 2004. Disponivel em: < http.//www.ibict.br/cienciadainformacao/viewarticle.php?id= 3034tlayout=abstract > . Acesso 11 dez. 2004.

. Gestão da qualidade em Serviços de Informação no Brasil: estabelecimento de un modelo de referênncia baseado nas diretrizes da IIBR ISO $\overline{9001.2005, ~} 247$ f. Tese (Doutorado em Ciências da Comunicação) - Escola de Comunicações e Artes da Universidade de São Paulo, São Paulo, 2005. Disponivel em: < http://wwww.teses.usp.br/> Acesso 18 fev. 2006.

. O profissionalda Informação no Sistema da Qualidade nas Empresas: um novo espaço para atuação com ênfase no controle de documentos e regisistros da Qualiddade. 1998, 131 f.Dissertação (Mestrado em Ciências da Comunicação) - Escola de Comunicaçōose e Artes da Universidade de São Paulo, SãoPaulo, 1998. Disponivel em: < http://wwww.teses.usp..br/teses/disponiveis/27/27143/tde-16062004-152236/publico//alls1.pdf> .Acesso 30 nov. 2004.

VALLS, Valéria Martin; VERGuUEIRO, Waldomiro. A gesesão da Qualidade em Serviços de Informação no Brasil: una revisão de literatura. Perspectivas em Ciênecia da Informaģãa. Belo Horizonte, v. 3, n. 1, p. 47-59. jan./jun. 1998. Disponível em: < http://www.eci.ufmg.br/pcionline/ viewarticle.php? $\mathrm{id}=191$ clayout $=$ abstract $>$. Acesso 8 fev. 2006 .

VANII, Nadia. Ambiente de qualidade em uma biblioteca universitária: aplicação do 5 S e de um estilo participativo de administração. Ciênncia da Informaçãa, Brasilia, v. 28, n. 3, set/dez. 1999, p. 333-9. Disponivel em: < http.//www.ibict.br/cienciadainformacao/viewarticle.php?id = 333flayout = abstract $>$. Acesso 4 out.2004.

VERGUEIRO, Waldomiro. Gestãoda qualidade em bibliotecas públicas. o difíici caminho para as instituições brasileiras. São Paulo: APB, 1995. (Ensaios APB, ก. 25).

. 0 ohar do cliente como fator de qualidade para a gestão de bibliotecas universitárias: estudos de caso em instituiçōes brasileiras. In:

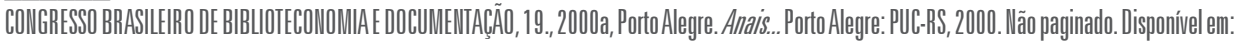
$<$ hittp://www.biblioestudantes.hpg.ig.com.br/texto_76.pdf > Acesso 6 out.2004. $\overline{\text { Paulo, 2000h. }}$.

Qulalidade em serviços de informação. 2000, 222t. Tese (Livre Docência) - Escola de Comunicações e Artes da Universidade de São Paulo, São . Qualidade em servịgos de informą̧ãa. São Paulo: Arte f́ Ciência, 2002.124p.

Qualidade ell serviçcos de informaçãa: o foco no cliente. São Paulo: APB, 2000c. 2 v. (Ensaios APB, n. 74-75).

Serviços ao cliente em bibliotecas universitárias brasileiras, com estudo de caso sob o enfoque na melhoria contínua. Revista Brasilerira de Biblioteconomia e Documentação, São Paulo, v. 1, n. 2, p. 48-59, 2000d (Nova Série).

VERGUEERO, Waldomiro; BELLUZZO, Regina Célia Baptista. Indicadores de qualidade em bibliotecas universitárias em face da globalização da informação. In:

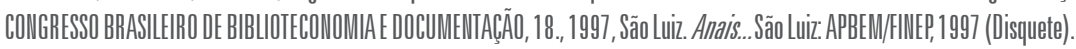

VERGUEIRO, Waldomiro; CARVALHO, Telma de. Definição de indicadores de qualidade: a visão dos administradores e clientes de bibliotecas universitárias. Perspectivas emlil Liência da Informacãoa, Belo Horizonte, v. 6, n. 1, p. 27-40, jan.jun. 2001.

. Indicadores de qualidade em bibliotecas universitárias brasileiras: o ponto de vista dos clientes. In: CONGRESSO BRASLLEIRO DE BIBLLOTECONOMIA

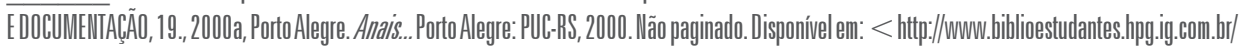
texto_55.pdf >.Acesso 6 out. 2004.

Gestão da Qualidade en bibliotecas universitárias brasileiras: un enfoque na certificação. In: SEMINÁRIO NACIONAL DE BIBLIOTECAS UNIVERSITÁRIIAS, 12., 2002, Recife. Anais... Recife:SWBU, 2002a, Não paginado (CD-ROM).Disponivel em: < hhttp://wwww.utpe.br/snbu/ddocs/142.a.pdf > . Acesso 6 out. 2004.

.Programas de calidad em las hibliotecas brasileñas: panoramas y perspectivas. Scire, Zaragoza, v. 9, n. 1,p. 75-83, ene.jjun. 2003. 